\title{
Hunting sites as ecological traps for coots in southern Europe: implications for the conservation of a threatened species
}

\author{
Alejandro Martínez-Abraín ${ }^{1,2, *}$, Covadonga Viedma ${ }^{1,2}$, Miguel A. Bartolomé $^{1,2}$, \\ Juan Antonio Gómez ${ }^{2}$, D. Oro ${ }^{1}$ \\ ${ }^{1}$ Institut Mediterrani d'Estudis Avançats IMEDEA (CSIC-UIB), Miquel Marquès 21, 07190 Esporles, Majorca, Spain \\ ${ }^{2}$ Centro de Recuperación de Fauna Granja de El Saler, Conselleria de Territorio y Vivienda, Avda. de los Pinares 106, \\ 46012, El Saler, Valencia, Spain
}

\begin{abstract}
Ecological traps, in combination with other factors, can reduce population sizes and even lead to local extinction. Here, we present the first evidence that hunting sites can act as ecological traps for waterfowl: wintering common coots Fulica atra were preferentially attracted to hunting sites in southern European wetlands, and showed decreasing population trends in these sites, compared to non-hunting sites. We demonstrate that the supply of energy-rich supplementary food (grain) triggered the trap. We also show that a behavioural mechanism, acting as an evolutionary load (the tendency to form mixed coot flocks during the winter), decreased population size of a threatened waterfowl species, the crested coot F. cristata. Our results suggest the use of precautionary policies regarding supplementary food in coot and associated diving-duck species, if negative conservation impacts are to be avoided.
\end{abstract}

KEY WORDS: Ecological trap - Evolutionary load - Management - Waterfowl hunting · Wetlands . Conservation $\cdot$ Coots $\cdot$ Supplementary feeding

\section{INTRODUCTION}

Ecological traps are a specific type of evolutionary trap, in which organisms make poor habitat choices, based on cues that formerly correlated with habitat quality but no longer do, mostly due to rapid human alteration of the environment (Dwernychuk \& Boag 1972, Schlaepfer et al. 2002). In an ecological trap scenario, animals choose bad habitats because they are guided by misleading habitat quality cues, whereas in a sink scenario animals avoid bad habitats because environmental cues are not misleading (Dias 1996, Battin 2004). Ecological traps therefore exist when (1) individuals can choose between a high-quality and a low-quality habitat and are guided by misleading cues to choose the low-quality habitat, and (2) this maladaptive habitat selection leads to reduced survival or reproduction, compared to the probable outcome if the high-quality habitat had been selected, or even to local population extinction(Battin 2004). A good example of an ecological trap that fulfils these theoretical requirements is given in experimental studies on habitat selection in insects (Horváth \& Zeil 1996, Kriska et al. 1998).

Historically, hunters have attracted waterfowl by means of decoys, together with other strategies such as supplementary feeding (Harvey et al. 1995, Newton 2006). To date, little has been reported regarding the role of hunting as a generator of ecological traps. Delibes et al. (2001) postulated that hunting can convert high-quality sites into 'attractive sinks', and Schlaepfer et al. (2002) suggested that hunting could act as an evolutionary trap. Here we hypothesize that waterfowl hunting could make hunting sites ecological traps for wintering common coots Fulica atra, considering that waterfowl hunters in Mediterranean wetlands 
provide wintering ducks and coots with energy-rich supplementary food (i.e. grain), and that this may be a misleading habitat quality cue, leading to reduced survival. In addition, since the endangered crested $\operatorname{coot} F$. cristata tends to form mixed flocks with common coots during the winter (Smith \& Peacock 1990, Reed \& Dobson 1993, Aguilar-Amat \& Raya 2004), the presence of common coots in hunting sites could extend the negative effects of hunting to crested coots (Schlaepfer et al. 2005). To test this hypothesis, we predict that (1) wintering flocks of coots are larger in hunting sites baited with artificial food than in non-hunted sites, and (2) following the start of the hunting season, coot abundance in hunting sites decreases more rapidly than in nonhunted areas (Robertson \& Hutto 2006).

\section{MATERIALS AND METHODS}

Testing coot preference for hunted sites. We studied site preferences of coot flocks in 49 specific sites from the 7 major wetlands along the Mediterranean coast of the Iberian Peninsula (Fig. 1), including sites with regular presence and absence of coots. At each site, approximately 10 fortnightly counts of coots were performed to estimate abundance, from the end of September 2004 to the end of January 2005 ( $\mathrm{n}=449$ counts), hence including the whole hunting season (mid-October to the end of January). Counts were performed synchronically (within a $2 \mathrm{~d}$ range) at all sites in order to prevent double counting between sites. A sampling of physical-chemical variables (i.e. dissolved oxygen, water temperature, conductivity and $\mathrm{pH}$ ) was performed during the months of December and January to account for water quality, since macrophytes (a major food resource for coots) typically grow in high quality waters. We also measured physiographic features such as water depth (because coots feed on submerged macrophytes) and flooded surface (because some diving species are known to prefer large water masses during the winter) (Paracuellos 2006). Food availability variables were also measured. Specifically, we recorded the relative abundance of submerged macrophytes, categorized from 0 to 3 depending on the relative degree of cover as observed by visual inspection $(0=0 \%, 1=10-40 \%, 2=40-70 \%, 3=70-100 \%)$, and the supply of supplementary food (rice, oats, sorghum, maize, among other items, supplied by hunters either as a mix or individually) as presence/absence. The hunting regime of each site (hunting/no hunting) was also recorded as a measure of human disturbance (see Table 1).

Testing the reduction in abundance of coots visiting hunted vs. non-hunted sites. To test for the differential abundance of common coots in hunted and

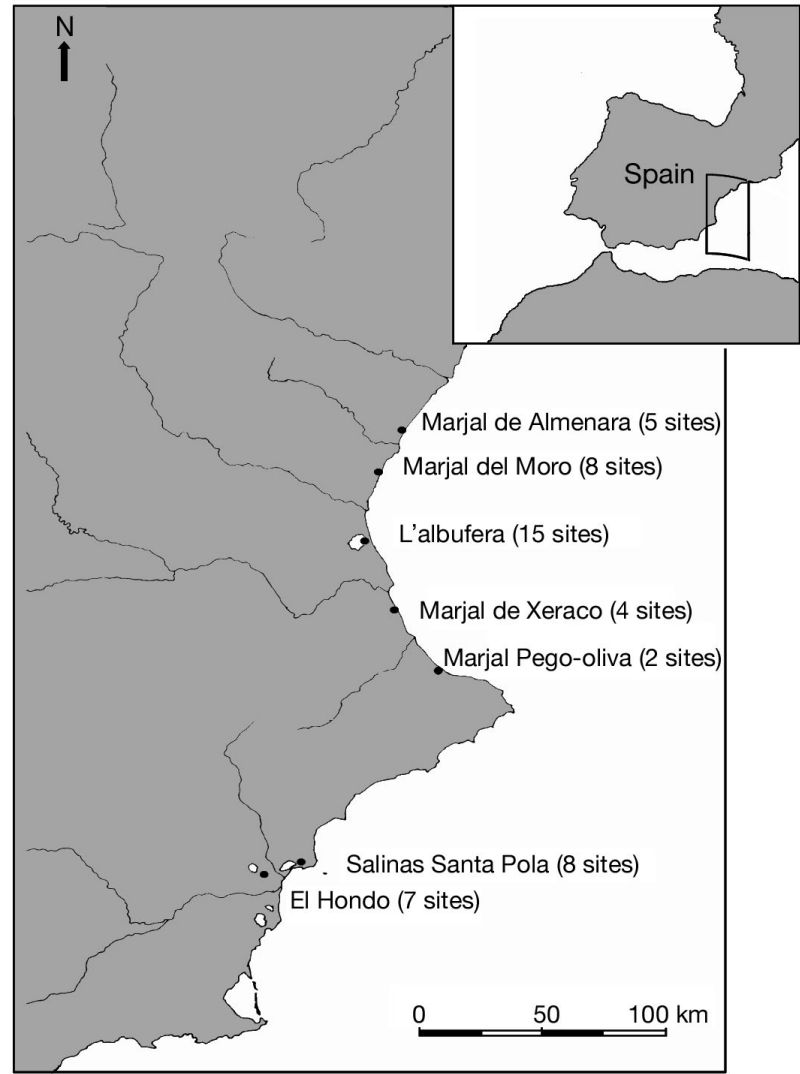

Fig. 1. The wetlands, and number of sites in each wetland, used to analyze habitat preferences of coots during wintering at the study area in Eastern Iberia (western Mediterranean)

non-hunted sites we first performed a repeated-measure ANOVA using counts of wintering coots as a dependent variable and hunting regime (hunting/ non-hunting) as an independent variable (Visauta \& Martori 2003). We then compared the fortnightly change in numbers of coots in both types of zones during the winter season. Monitoring of coots was performed in all major wetlands in the region, including many hunting sites (Fig. 1). Coots, unlike many duck species, stay at hunting sites during the day and hence can be counted in the daytime both at hunting and non-hunting sites.

During a continuous programme of monitoring of crested coots in the field at all study sites (performed during the period 2000 to 2005 within a specific project for the conservation of crested coots) substantial effort was devoted to (1) determining the number of common coots flocking with crested coots and (2) detecting dead crested coots. The search for dead crested coots was done on a fortnightly basis throughout the whole year at each site. Searches were performed using a scope to inspect the water masses of each site and concentrating particularly on the shorelines. The cause of 
death of crested coots found in the field was determined, when necessary, by experienced veterinarians. At hunting sites to which managers would not give us free access, meetings were held with hunters in order to inform them about the ongoing reintroduction program of crested coots, the main field characteristics of the species and the importance of reporting the killing of marked or unmarked crested coots.

Statistical analysis. Robust estimates of central tendency: Given that counts typically follow a Poisson distribution we used the sample $\alpha$-Winsorized mean (with $\alpha=0.1$ ) as a robust estimator of central tendency (Hill \& Dixon 1982, García 2005) as well as the median. We verified, through 1000 bootstrap iterations, that the distribution of the $\alpha$-Winsorized mean number of coots in all 49 study sites followed a normal distribution (Kolmogorov-Smirnoff $Z=1.34 ; \mathrm{p}=0.054$ ).

Testing for independence of sites: To test for independence of sampled sites we performed a test of runs above and below the mean on the sequence of the $\alpha$ Winsorized mean number of coots, with wetlands ordered from north to south (Zar 1999). The non-parametric test on serial randomness suggested that our data were extracted from independent sites $(Z=$ $-0.188, \mathrm{p}=0.851$ ); where $Z$ is the normal deviate, for a normal approximation.

General Lineal Model to account for wintering habitat preferences: A General Linear Model (GLM) was fitted to data explaining the mean number of wintering coots (as described by the $\alpha$-Winsorized mean) at each site, as a function of all explanatory variables considered. Physical-chemical variables were reduced by means of a Principal Component Analysis (PCA) and the first 2 eigenvectors, explaining $72.8 \%$ of the variance, were introduced in the analysis. Physiographic features of the water masses were also reduced by means of a second $\mathrm{PCA}$, and the first and only eigenvector, explaining $59 \%$ of the variance, was taken. We considered the interaction between the 2 variables related to food availability to account for the differential influence of both food resources on the mean number of wintering coots. Interactions between each of the 2 types of food resources (both natural and artificial) and the hunting regime of the sites were also taken into account. Surface area of each site considered was not introduced into the GLM because sites were defined as parts of larger wetlands and we assumed that the surface area of the whole wetland, rather than the surface area of individual sites, could be affecting habitat selection by coots,. To account for the individual weight of each statistically significant variable, we reduced the model containing all statistically significant variables, using a backwards stepwise procedure, and checked the associated reduction in $\mathrm{R}^{2}$ (0.05 for inclusion and 0.10 for exclusion).
Poisson regression was used to study population trends of common coots during the winter in hunting and non-hunting sites. Robust estimates of central tendency and Poisson regression were obtained by means of $\mathrm{R}$ (www.r-project.org/). Bootstrapping was performed by means of an ad hoc macro in a spreadsheet which randomly resampled (using a random number generator to choose the observations) with replacement from the original sample (Quinn \& Keough 2004). All other analyses (PCAs, GLM and serial randomness) were performed by means of the statistical package SPSS vs. 13.0.

\section{RESULTS}

\section{Coot habitat preferences}

The results of our linear model indicated a statistically significant effect of food availability (both as relative abundance of submerged macrophytes and as presence/absence of supplementary food) on the mean number of wintering coots, as well as of the interaction between both variables explaining food availability. The GLM also identified a statistically significant effect of hunting regime, as well as of the interaction between the relative abundance of submerged macrophytes and the hunting regime (Table 1). None of the other environmental variables (including physical-chemical or physiographic features) or the interaction between supplementary food and hunting regime were found to be statistically significant (Table 1). Surprisingly, only the removal of the interaction between submerged macrophytes and hunting regime had any substantial reduction on the variance explained (ca. 20\% change in $\mathrm{R}^{2}$ corrected vs. no change with the individual removal of all other variables), suggesting an important influence of this interaction on the model. In fact, although in the absence of submerged macrophytes the median number of wintering coots was higher in hunting sites than in non-hunting sites, when macrophytes were present (taking into account sites with presence of macrophytes either from categories 1, 2 or 3 ), the median number of coots in hunting sites increased 4 -fold, whereas it remained almost equal in non-hunting sites (Fig. 2a). Hence, to fully understand the influence of this interaction it was necessary to take into account the effect of the interaction between the relative abundance of submerged macrophytes and the presence/absence of supplementary food. As shown in Fig. 2b, when supplementary food was supplied (taking into account sites with presence of macrophytes from categories 1,2 or 3 ) the number of win- 
Table 1. Explanatory variables incorporated in a General Linear Model testing for the influence of trophic, environmental and anthropogenic variables on the $\alpha$-Winsorized mean number of common coots wintering in 49 study sites of the western Mediterranean coast (Eastern Iberian Peninsula) and results of the analysis. Statistically significant results are in bold. PCA: Principal Component Analysis; $R^{2}=0.953\left(R_{\text {corrected }}^{2}=0.927\right)$

\begin{tabular}{|c|c|c|c|}
\hline $\begin{array}{l}\text { Variable type, no. } \\
\text { and name }\end{array}$ & Description & $F$ & $\mathrm{p}$-value \\
\hline & Corrected model & 36.77 & 0.000 \\
\hline & Intercept & 120.70 & 0.000 \\
\hline \multicolumn{4}{|l|}{ Food resources } \\
\hline 1. Macrophytes & $\begin{array}{l}\text { Relative abundance of sub- } \\
\text { merged macrophytes (cate- } \\
\text { gorized as } 0,1,2 \text { or } 3 \text { ) }\end{array}$ & 85.76 & 0.000 \\
\hline 2. Suppl. food & $\begin{array}{l}\text { Presence/absence of } \\
\text { supplementary food }(0 / 1)\end{array}$ & 19.21 & 0.000 \\
\hline \multicolumn{4}{|l|}{ Environment } \\
\hline 3. PCA1 & $\begin{array}{l}\text { First eigenvector of a PCA of } \\
\text { the physical-chemical features } \\
\text { of the water (dissolved oxygen } \\
\text { and pH gradient) }\end{array}$ & 0.30 & 0.589 \\
\hline 4. PCA2 & $\begin{array}{l}\text { Second eigenvector of a PCA } \\
\text { on the physical-chemical } \\
\text { features of the water (water } \\
\text { temperature and conductivity } \\
\text { gradient) }\end{array}$ & 1.41 & 0.244 \\
\hline 5. PCA3 & $\begin{array}{l}\text { First eigenvector of a PCA on } \\
\text { the physiographic features of the } \\
\text { site (water depth and flooded } \\
\text { surface gradient) }\end{array}$ & 1.11 & 0.737 \\
\hline \multicolumn{4}{|l|}{ Human disturbance } \\
\hline 6. Hunting & $\begin{array}{l}\text { Hunting regime of the site } \\
\text { (presence/absence) }\end{array}$ & 69.755 & 0.000 \\
\hline \multicolumn{4}{|l|}{ Interactions } \\
\hline & Interaction between variables 1 and 2 & 7.169 & 0.003 \\
\hline & Interaction between variables 1 and 6 & 35.562 & 0.000 \\
\hline & Interaction between variables 2 and 6 & 0.196 & 0.661 \\
\hline
\end{tabular}

Table 2. Results of a repeated-measure ANOVA using all the counts of coots performed in all 49 wintering sites as a dependent variable. Statistically significant interactions are in bold. Wilk's lambda is a quantity ranging from 0 to 1 measuring the amount of variability among the data that is not explained by the effect of the levels of the factor

\begin{tabular}{|lccc|}
\hline Effect & $\begin{array}{c}\text { Wilk's } \\
\text { lambda }\end{array}$ & $F$ & p-value \\
\hline Macrophytes & $\mathbf{0 . 0 0 0}$ & $\mathbf{2 5 . 7 4}$ & $\mathbf{0 . 0 0 0}$ \\
Supplementary food & $\mathbf{0 . 0 1 2}$ & $\mathbf{1 6 0 . 4 2}$ & $\mathbf{0 . 0 0 0}$ \\
Hunting & $\mathbf{0 . 0 0 2}$ & $\mathbf{1 1 1 6 . 5 8}$ & $\mathbf{0 . 0 0 0}$ \\
PCA1 (dissolved oxygen and pH gradient) & 0.907 & 0.20 & 0.979 \\
PCA2 (water temperature and conductivity & 0.890 & 0.25 & 0.964 \\
gradient) & 0.783 & 0.55 & 0.780 \\
PCA3 (water depth and flooded surface & & & \\
gradient) & & & \\
\hline
\end{tabular}

tering coots was much larger in sites with macrophytes than in sites without macrophytes (taking into account sites with category 0).

\section{Differential abundance of coots}

Using repeated-measures ANOVA we detected a statistically significant effect of the hunting regime of sites on the whole series of coot counts (Table 2). Specifically, the trend of the number of coots in hunting sites during the winter season was negative, whereas it was positive in non-hunting sites. This was shown by the slope in a Poisson regression between time and number of coots (negative in hunting sites and positive in unhunted sites) (see also Fig. 3). In fact, the total number of common coots increased by $116 \%$ in non-hunting sites from the beginning to the end of the season compared to a $73 \%$ decrease in hunted sites. However, the decrease in the number of coots in hunted sites was of a much larger magnitude than the increase in number of coots in nonhunting sites.

\section{Implications for an endangered species}

We found that crested coots were proportionally more numerous in mixed flocks than alone in hunting sites than in non-hunting sites (Fig. 4). Also, hunting turned out to be the main cause of death of crested coots during the hunting season (October to the end of January) with $80 \%$ of known deaths being assigned to shooting $(\mathrm{n}=10)$. Although game species typically show a proportionally large number of recoveries (Boyd \& Hyslop 1985, Conroy 1985, Guillemain et al. 2006), this is probably not the case with crested coots, because hunters were very unwilling to report hunting mortality of marked crested coots since they risked being penalized for killing a threatened species. Hence, we assumed that estimates of 

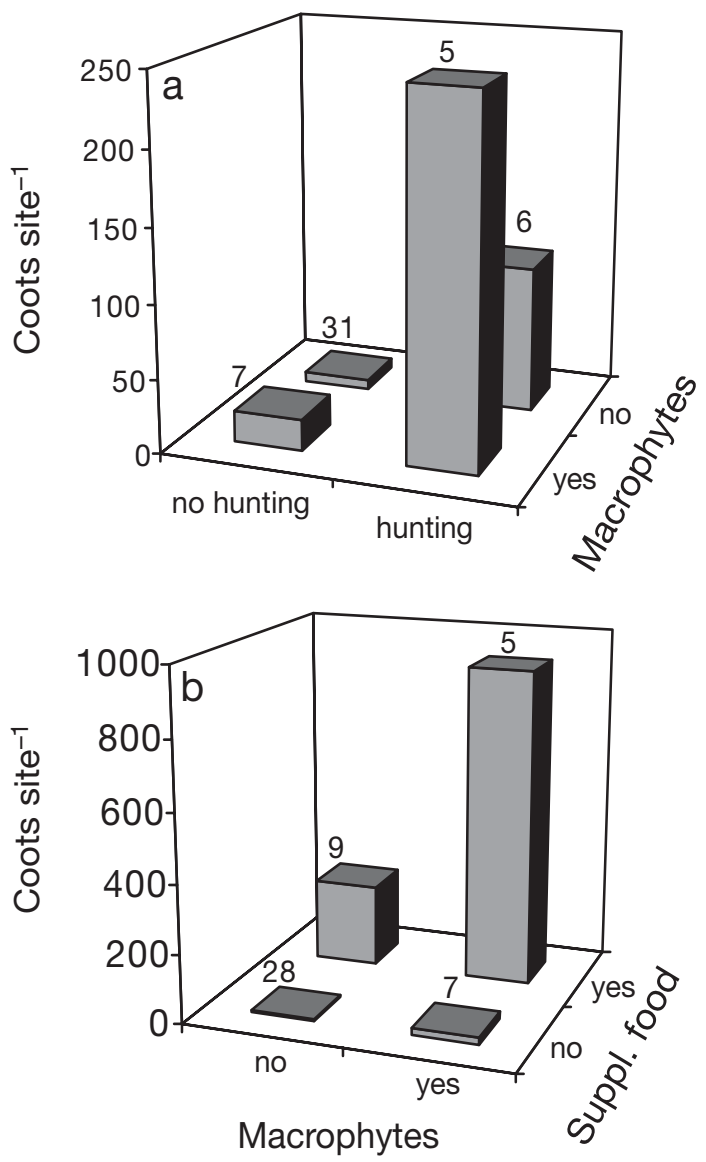

Fig. 2. Fulica cristata and Fulica atra. Median number of coots counted per site depending on (a) the interaction between presence/absence of macrophytes and hunting regime of the sites; and (b) the interaction between presence/absence of macrophytes and presence/absence of supplementary (suppl.) food. Numbers on columns show the number of sites which have each combination of the 2 variables

crested coot mortality by hunting were not overestimated compared to those of natural mortality in nonhunted sites, although the data were not corrected for detection probability.

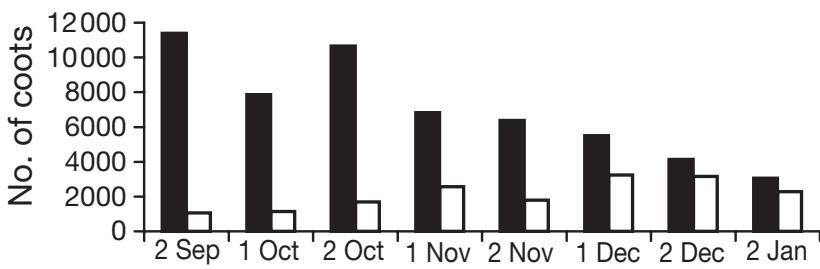

Fig. 3. Fulica atra. Total number of common coots counted at hunting sites (black bars) and non-hunting sites (white bars) during the winter season of 2004-2005. The first fortnightly census in January is not included because not all sites were counted

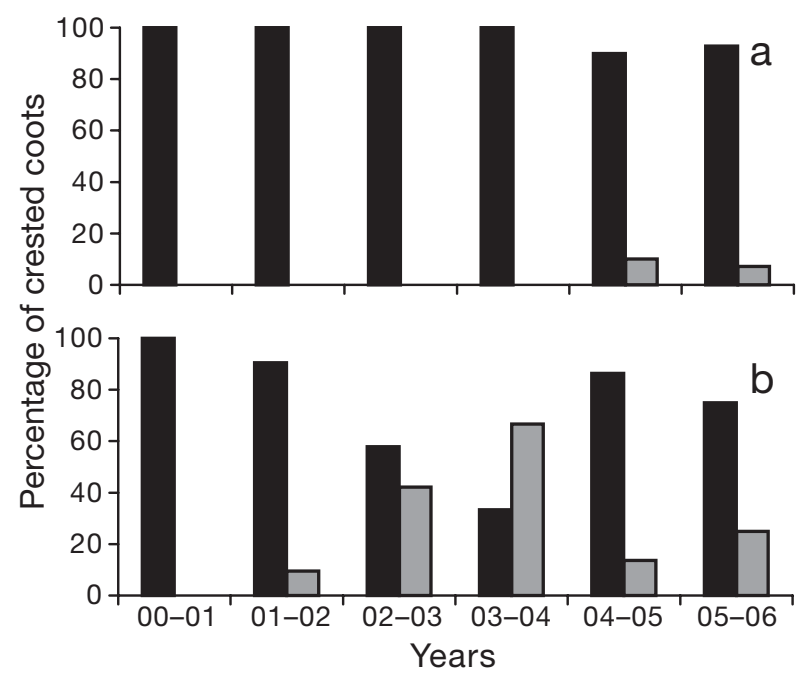

Fig. 4. Fulica cristata and Fulica atra. Percentage of crested coots wintering in mixed flocks with common coots (black bars) and wintering alone (grey bars) in (a) hunting sites and (b) non-hunting sites, over time (2000 to 2006). We defined a mixed flock as a dense group of $>10$ ind. in all

\section{DISCUSSION}

\section{Habitat preferences}

Results show that wintering coots reached much higher population numbers in wetland sites where hunting occurred than in non-hunting sites. The provision of supplementary food in hunting sites of high quality (i.e. those with macrophytes available) seems to be a key factor driving wintering coots' selection of hunting sites.

Hunting sites (22\% of sites studied) held $72 \%$ of the wintering coots. Additionally, the percentage of coots (in relation to the sum of the maximum number of coots counted at each site) was much larger at hunting sites (81 vs. 19\%) although the number of good sites (i.e. sites with high food availability) with and without hunting was roughly equal (9 and 11, respectively) and the total surface occupied by high-quality non-hunted sites was much larger (393 ha) than that occupied by high-quality hunting sites (170 ha). Thus, although coots are likely to be disturbed by hunting they preferred wintering in hunting sites over non-hunting sites, probably as a result of high food availability (supplementary feed ranged from 8 to $77 \mathrm{~kg} \mathrm{ha}^{-1}$ supplied weekly during the whole hunting season; C. Viedma, M. A. Bartolomé unpubl. data).

\section{Differential number of coots}

Through indirect evidence we have also shown that hunting sites could have negative demographic consequences for coots, because the number of coots in 
hunting sites showed substantial decreasing local population trends from the beginning to the end of the wintering period, as opposed to the positive trends in the non-hunting sites of the region. Our monitoring scheme allows us to be confident that the simple transfer of individuals from hunted to non-hunted sites cannot explain this pattern, because the decrease in hunted sites was of a much greater magnitude than the increase in non-hunted sites. Therefore, the decrease during the hunting season could only be due either to long-distance dispersal beyond the study area or to hunting mortality. Although we cannot discount longdistance dispersal, we speculate that local mortality is more likely to account for the population decline in hunted sites, for a number of reasons. Firstly, coots mostly move south during autumn months, so we would not expect coots present at hunting sites during the mid-winter months to perform long distance migrations (Díaz et al. 1996). Secondly, evidence based on 600 crested coots individually marked with neck bands and released by us in wetlands of the study area from 2000 to 2005, indicate that only 14 birds (2.3\%) moved during the hunting season to other wetlands within their Iberian wintering grounds. None of these were observed in northern Africa, suggesting that a similar pattern is likely for common coots, since crested and common coots form mixed flocks in winter. Lastly, even though no precise hunting statistics are available, coot hunting has historically been very intensive in southern European wetlands. The killing of several thousand coots annually at the beginning of the twentieth century in just one of our study sites was reported by Bru (1913) and Bernis (1964). Coot hunting is especially intensive within the study area because coots are a highly valued catch for hunters. In addition, hunters take advantage of the particular anti-predatory response of coots (i.e. diving rather than flight). Our data on coot harvesting are very limited, owing to the reluctance of hunters to provide information and the lack of official data, but also suggest that a large percentage of common coots are killed annually. In just one of our study sites, $20 \%$ of the coots present at the beginning of the hunting season had been killed by the third week of hunting (C. Viedma unpubl. data). Nevertheless, hunters manage not to deplete the whole coot flock during the first weeks of hunting because they use them to lure on diving duck species throughout the hunting season. Also, high mortality probabilities of first-year birds due to hunting have been reported in the literature (0.79 in hunting sites vs. 0.32 in nonhunted sites; Cramp \& Simmons 1980).

Therefore, considering that coots clearly preferred hunted over non-hunted habitat, owing to the availability of supplementary food, and that this maladaptive habitat selection probably resulted in higher mortality in hunting than in non-hunting sites, we suggest that waterfowl hunting sites are most likely acting as ecological traps, triggered by the supply of energy-rich food resources. This is, to the best of our knowledge, the first time that hunting has been linked with ecological trap theory, following the suggestion by Delibes et al. (2001) that hunting can transform high-quality habitats into traps ('attractive sinks') increasing adult mortality. These results indicate that coot hunting (and most likely the hunting of other waterfowl species with social habits during the winter) might not be a case of compensatory mortality (see Nichols et al. 1984, Nichols 1991) but rather of additive mortality, at least in southern European wetlands (Kokko 2001, Novaro et al. 2005).

\section{Implications for an endangered waterfowl species}

Although crested coots did not show a clear preference for hunting sites (Fig. 5), their tendency to form mixed flocks with the common coot meant that crested coots were killed mistakenly, as both species resemble each other in the field. In fact, the main known cause of crested coot mortality during the implementation of the reintroduction project was hunting, although this does not necessarily mean that hunting actually was the main cause of mortality, since a substantial percentage of crested coots died of unknown causes.

Thus, although there is no evidence of huntinginduced ecological trapping for crested coots (probably owing to the small size of the released population), the trap affecting common coots also affected crested coots negatively due to their behavioural mechanism of forming mixed flocks (Danielson \& Gaines 1987, Reed \& Dobson 1993).

Our results are consistent with the idea that traps can not only cause decreasing local population trends but most importantly can also threaten small-size local populations with extinction (Kokko \& Sutherland 2001, Kristan 2003, Battin 2004). This can be the case in particular when other negative factors occur, such as temporal scarcity of food owing to unfavourable weather or inap-

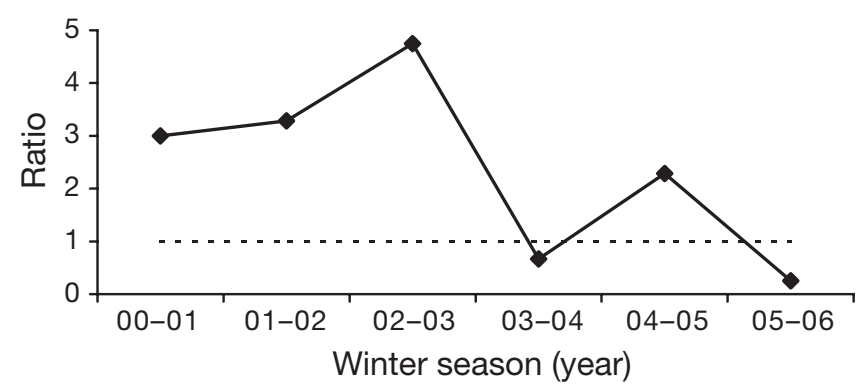

Fig. 5. Fulica cristata. Ratio of the number of crested coots in non-hunting sites over the number of crested coots in hunting sites during the winter. (---) 1:1 ratio 
propriate human management of wetlands. In our case, after we had released ca. 600 crested coots during the period 2000 to 2005, only 9 pairs bred in the wild during the breeding season of 2005. This low success level can be partially attributed to hunting, since a large percentage of the coots which survived the difficulties associated with adapting to the non-hunted habitat where they were released (G. Tarecchia, C. Viedma, A. MartínezAbraín, M. A. Bartolomé, J. A. Gómez, D. Oro unpubl. data) died at hunting sites afterwards.

\section{Conclusions for management practices}

The results of our study clearly suggest that the adoption of precautionary policies regarding the use of supplementary food in waterfowl hunting will be needed if adverse conservation impacts are to be avoided. Environmental agencies could ban the supply of supplementary food to prevent maladaptive habitat choice by wintering coots (as is commonly done, for example, in North American countries), although this option may be socially costly, depending on the region. In addition, a moratorium on the hunting of common coots should be implemented at least until the reintroduced population of crested coots reaches a viable population size. Alternatively, while hunters continue to manage their sites and provide winter food in southern European wetlands, it would be advisable at least to imitate the hunters' strategy in high-quality, non-hunting sites, providing surveillance, supplementary food and decoys in sites where hunting is not allowed. Providing highquality sites for wintering, as is commonplace for breeding (Novaro et al. 2005), would benefit both coot species, and possibly many other waterfowl species, including in particular diving duck species (Aythya spp.), which are typically found associated with coots as 'legitimate' residents of hunting sites, and show declining trends all over Europe (BirdLife International 2004).

Acknowledgements. We are grateful to Andy Green, Bruce Robertson, Giacomo Tavecchia, Miguel Delibes and David Serrano for constructive comments on a first draft of the manuscript. We also thank Blanca Sarzo and Jose I. Díes for their help during field monitoring of coots, and the hunting wardens and managers of the Vedado de Silla (Ayuntamiento de Silla), the staff of the La Granja Recuperation Centre (especially to Elena Villuendas, Cati Gerique and Natalia Ramón). Our thanks is also due to all the institutions and their volunteers involved in the counting of common coots: Parque Natural de la Albufera, Parque Natural Pego-Oliva, Parque Natural de las Salinas de Santa Pola, Parque Natural de El Hondo, Ayto. de Elche and SEO/BirdLife. This study was partially funded by Conselleria de Territori i Habitatge (Generalitat Valenciana) and the EU project 'LIFE 99 NAT/E/006393 Reintroduction of crested coot in 2 SPAs of the Comunidad Valenciana'.

\section{LITERATURE CITED}

Aguilar-Amat J, Raya C (2004) Crested coot (Fulica cristata) report. In: Madroño A, González C, Atienza JC (eds) Libro rojo de las aves de España. Dirección General para la Biodiversidad-SEO/BirdLife, Madrid, p 199-202

Battin J (2004) When good animals love bad habitats: Ecological traps and the conservation of animal populations. Conserv Biol 18:1482-1491

Bernis F (1964) Información española sobre anátidas y fochas. Sociedad Española de Ornitología, Madrid

BirdLife International (2004) Birds in Europe: population estimates, trends and conservation status. BirdLife conservation series No.12. BirdLife International, Cambridge

Boyd H, Hyslop C (1985) Are hunting losses of young black ducks (Anas rubripes) too high? In: Morgan BJT, North PM (eds) Statistics in ornithology. Springer-Verlag, Berlin, p 181-195

Bru F (1913) Notas de Caza, Valencia

Conroy MJ (1985) Maximum likelihood methods for investigating reporting rates of rings on hunter-shot birds. In Morgan BJT, North PM (eds) Statistics in ornithology. Springer-Verlag, Berlin, p 215-241

Cramp S, Simmons KEL (1980) The birds of the western Palearctic, Vol II. Oxford University Press, Oxford

Danielson BJ, Gaines MS (1987) The influences of conspecific and heterospecific residents on colonization. Ecology 68: 1778-1784

Delibes M, Gaona P, Ferreras P (2001) Effects of an attractive sink leading into maladaptive habitat selection. Am Nat 158:277-285

Dias PC (1996) Sources and sinks in population biology. Trends Ecol Evol 11:326-329

Díaz M, Asensio B, Tellería JL (1996) Aves Ibéricas I. No paseriformes. J.M. Reyero Editor, Madrid

Dwernychuk LW, Boag DA (1972) Ducks nesting in association with gulls: an ecological trap? Can J Zool 50:559-563

García A (2005) Métodos avanzados de estadística aplicada: métodos robustos y de remuestreo. Universidad Nacional de Educación a Distancia, Madrid

Guillemain M, Arzel C, Mondain-Monval JY, Schricke V, Johnson AR, Simon G (2006) Spring migration dates of teal Anas crecca ringed in the Camargue, southern France. Widl Biol 12:163-169

Harvey WF, Hindman LJ, Rhodes WE (1995) Vulnerability of Canada geese to taxidermy-mounted decoys. J Wildl Manag 59:474-477

Hill M, Dixon WJ (1982) Robustness in real life: a study of clinical laboratory data. Biometrics 38:377-396

Horváth G, Zeil J (1996) Kuwait oil lakes as insect traps. Nature 379:303-304

Kokko H (2001) Optimal and suboptimal use of compensatory responses to harvesting: timing of hunting as an example. Wildl Biol 7:159-168

Kokko H, Sutherland WJ (2001) Ecological traps in changing environments: ecological and evolutionary consequences of a behaviourally mediated Allee effect. Evol Ecol Res 3: $537-551$

Kriska G, Horvath G, Andrikovics S (1998) Why do mayflies lay their eggs en masse on dry asphalt roads? Waterimitating polarized light reflected from asphalt attracts Ephemeroptera. J Exp Biol 201:2273-2286

Kristan WB (2003) The role of habitat selection behaviour in population dynamics: source-sink systems and ecological traps. Oikos 103:457-468

Newton I (2006) Can conditions experienced during migration limit the population levels of birds? J Ornithol 147:146-166 
Nichols JD (1991) Extensive monitoring programmes viewed as long-term population studies: the case of NorthAmerican waterfowl. Ibis 133 SI:89-98

Nichols JD, Conroy MJ, Anderson DR, Burnham KP (1984) Compensatory mortality in waterfowl populations: a review of the evidence and implications for research and management. Trans N Am Wildl Nat Resour Conf 49: 535-554

Novaro AJ, Funes MC, Walter RS (2005) An empirical test of source-sink dynamics induced by hunting. J Appl Ecol 42: 910-920

Paracuellos M (2006) How can habitat selection affect the use of a wetland complex by waterbirds? Biodivers Conserv 15:4569-4582

Quinn GP, Keough MJ (2004) Experimental design and data analysis for biologists. Cambridge University Press, Cambridge

Editorial responsibility: Stuart Bearhop,

Belfast, UK
Reed JM, Dobson AP (1993) Behavioural constraints and conservation biology: conspecific attraction and recruitment. Trends Ecol Evol 8:253-256

Robertson BA, Hutto RL (2006) A framework for understanding ecological traps and an evaluation of existing evidence. Ecology 87:1075-1085

Schlaepfer MA, MC Runge, Sherman PW (2002) Ecological and evolutionary traps. Trends Ecol Evol 17:474-480

Schlaepfer MA, Sherman PW, Blossey B, Runge MC (2005) Introduced species as evolutionary traps. Ecol Lett 8:241-246

Smith AT, Peacock MM (1990) Conspecific attraction and the determination of metapopulation colonization rates. Conserv Biol 4:320-323

Visauta B, Martori JC (2003) Análisis estadístico con SPSS para Windows. McGraw Hill, Madrid

Zar JH (1999) Biostatistical Analysis. Prentice Hall, Upper Saddle River, NJ

Submitted: October 26, 2006; Accepted: May 9, 2007

Proofs received from author(s): May 30, 2007 